\title{
Expanding medicines for neurologic disorders on the WHO Model List
}

Kathryn Rimmer, MD

Hiral Shah, MD

Kiran Thakur, MD

Correspondence to

Dr. Thakur:

ktt2115@cumc.columbia.edu

\section{ABSTRACT}

The WHO Model List of Essential Medicines is a recommended formulary for high-priority diseases based on public health trends and epidemiology patterns. The biennial publication serves as a guide for countries, particularly low- and lower-middle-income countries, to develop their own national essential medicines list (EML), and many nongovernmental organizations base their medication supplies on the WHO EML. Over the last 40 years, WHO has expanded the EML in response to treatment gaps for infectious diseases, pediatrics, palliative care, and cancer. In contrast, neurotherapeutics are poorly represented on the Model List despite the global burden of neurologic disorders, which have continued to increase in the last decade. It is imperative that the neurology community advocate for more evidence-based neurologic medicines on the WHO EML. Equitable access to essential neurologic medicines is a crucial step toward reducing the treatment gap for high-burden neurologic disorders worldwide. Neurology ${ }^{\circledR}$ 2017;88:e87-e91

GLOSSARY

EML = essential medicines list; $\mathbf{L M I C}=$ low- and lower-middle-income countries; NGO = hongovernmental organization

The burden of neurologic disorders on the global population continues to increase, particularly in low- and lower-middle-income countries (LMICs). ${ }^{1}$ The most recent estimates from the Global Burden of Disease Study show that stroke is the second highest cause of mortality and morbidity worldwide. ${ }^{1,2}$ Migraine, meningitis, and dementia rank in the top 30 causes of disability-adjusted life-years, and epilepsy in the top 50, of 315 diseases and injuries studied. ${ }^{1}$ Numerous treatment gaps exist for high-burden neurologic disorders in LMICs, ${ }^{3}$ and improved access to essential neurologic medicines deserves prioritization.

The WHO publishes its Model List of Essential Medicines in order to guide developing countries in their national drug policies, ensure equitable access to essential medicines, and promote rational use of medicines. The essential medicines concept has inspired over 110 countries to generate a national essential medicines list (EML). In addition, many nongovernmental organizations (NGOs) that facilitate health care in resource-poor settings (e.g., United Nations High Commissioner for Refugees, Médecins Sans Frontières, and International Federation of Red Cross and Red Crescent Societies) accept donations and distribute medicines in accordance with the WHO EML. ${ }^{4}$ Medicines selected for the Model List are associated with increased global availability in both the public and private sectors when compared to nonessential medicines. ${ }^{5}$ The Model List has grown from 208 medicines in 1977 to over 400 medicines in the 2015 edition. It includes a core list of efficacious, safe, and cost-effective medicines relevant to a basic health care system, and a complementary list of medicines for which specialized diagnostic or monitoring facilities, specialist medical care, or specialist training are needed. ${ }^{6}$ While the WHO EML has expanded in response to treatment gaps for infectious diseases, pediatrics, palliative care, and cancer, neurologic disorders are poorly represented. Many neurotherapeutic options have not been adequately updated in accordance with evidence-based guidelines.

Neurologic disorders and WHO Model List coverage. The initial 1977 Model List includes 9 neurologic medicines that are classified into disease-specific categories (antimigraine, antiepileptic, and antiparkinsonism) and 11 other

From the Community and Global Neurology Program, Department of Neurology, Columbia University Medical Center, New York, NY. Go to Neurology.org for full disclosures. Funding information and disclosures deemed relevant by the authors, if any, are provided at the end of the article. 
medicines used to treat neurologic disorders that are classified by pharmacologic effect (antihypertensive, anticholinesterase, and diuretic). The 2015 Model List similarly maintains separation of neurologic medicines into disease-specific $(\mathrm{n}=15)$ and pharmacologic categories $(\mathrm{n}=11)$. These include 9 antiepileptic, 4 antimigraine, 2 antiparkinsonism, 5 antihypertensive, 2 antithrombotic, 1 lipid-lowering, 1 diuretic, and 2 anticholinesterase medicines. From 1977 to 2015 , there has been minimal change $(n=6)$ in the number of essential medicines for neurologic disorders (table 1). In contrast, essential medicines for infectious and neoplastic diseases have expanded with every EML revision. Advocacy, plentiful applications, and organization of anti-infective and anti-neoplastic medicines into disease-specific subtypes may have contributed to successful growth of those medication classes. ${ }^{7.8}$

There are many gaps in evidence-based neurotherapeutics on the 2015 Model List (table 2). Although antihypertensive and antithrombotic medicines for stroke prevention are represented on the WHO EML, recombinant tissue plasminogen activator is not included on the complementary list for acute treatment of ischemic stroke. In addition, first-line short-acting antihypertensives including labetalol and nicardipine are absent. Newer treatment options for other neurologic disorders, such as dopamine agonists for Parkinson's disease, lamotrigine for epilepsy, and sumatriptan for migraine, have been considered but were ultimately rejected for Model List inclusion. The Model List does not include medications for dementia, multiple sclerosis, neuropathic pain, essential tremor, or myasthenia gravis. Of all the neurologic medications, antiepileptic drugs are the most numerous type, but are limited to abortive benzodiazepines in the setting of acute seizure, agents with limited indications (i.e., magnesium sulfate and ethosuximide), or older agents known for substantial drug-drug interactions and teratogenicity.

The low rate of EML inclusion for neurologic medications is likely influenced by a relative paucity

Table 1 WHO Model List: Number of medications by class, ${ }^{a}$ 1977-2015

\begin{tabular}{|c|c|c|c|c|c|c|}
\hline Medication class & 1977 & 1979 & 1988 & 1998 & 2009 & 2015 \\
\hline Anti-infective & 55 & 55 & 65 & 81 & 120 & 139 \\
\hline Antineoplastic & 10 & 14 & 18 & 22 & 26 & 45 \\
\hline \multirow[t]{10}{*}{ Anticonvulsant/antiepileptic } & 5 & 6 & 6 & 8 & 8 & 9 \\
\hline & Carbamazepine & Carbamazepine & Carbamazepine & Carbamazepine & Carbamazepine & Carbamazepine \\
\hline & Diazepam & Diazepam & Diazepam & Clonazepam & Diazepam & Diazepam \\
\hline & Ethosuximide & Ethosuximide & Ethosuximide & Diazepam & Ethosuximide & Ethosuximide \\
\hline & Phenobarbital & Phenobarbital & Phenobarbital & Ethosuximide & Lorazepam & Lorazepam \\
\hline & Phenytoin & Phenytoin & Phenytoin & Magnesium sulfate & Magnesium sulfate & Magnesium sulfate \\
\hline & & Valproic acid & Valproic acid & Phenobarbital & Phenobarbital & Midazolam \\
\hline & & & & Phenytoin & Phenytoin & Phenobarbital \\
\hline & & & & Valproic acid & Valproic acid & Phenytoin \\
\hline & & & & & & Valproic acid \\
\hline \multirow[t]{5}{*}{ Antimigraine } & 1 & 1 & 3 & 4 & 4 & 4 \\
\hline & Ergotamine & Ergotamine & Aspirin & Aspirin & Aspirin & Aspirin \\
\hline & & & Ergotamine & Ergotamine & Ibuprofen & Ibuprofen \\
\hline & & & Paracetamol & Paracetamol & Paracetamol & Paracetamol \\
\hline & & & & Propranolol & Propranolol & Propranolol \\
\hline \multirow[t]{4}{*}{ Antiparkinsonism } & 3 & 3 & 2 & 2 & 2 & 2 \\
\hline & Carbidopa-levodopa & Carbidopa-levodopa & Biperiden & Biperiden & Biperiden & Biperiden \\
\hline & Levodopa & Levodopa & Carbidopa-levodopa & Carbidopa-levodopa & Carbidopa-levodopa & Carbidopa-levodopa \\
\hline & Trihexyphenidyl & Trihexyphenidyl & & & & \\
\hline Antihypertensive & 8 & 6 & 7 & 9 & 7 & 7 \\
\hline Antithrombotic & 0 & 0 & 0 & 2 & 2 & 3 \\
\hline Lipid-lowering agent & 0 & 0 & 0 & 0 & 0 & 1 \\
\hline Anticholinesterase & 2 & 2 & 2 & 2 & 2 & 2 \\
\hline
\end{tabular}

${ }^{a}$ Does not include all medication classes on the WHO Model List. 


\begin{tabular}{|c|c|c|c|c|c|c|c|c|c|c|}
\hline \multicolumn{11}{|c|}{ Table 2 WHO Model List coverage and gaps for neurologic disorders } \\
\hline Stroke & Dementia & $\begin{array}{l}\text { Parkinson } \\
\text { disease }\end{array}$ & Epilepsy & Multiple sclerosis & Headache & $\begin{array}{l}\text { Neuropathic } \\
\text { pain }\end{array}$ & Myasthenia gravis & $\begin{array}{l}\text { Essential } \\
\text { tremor }\end{array}$ & Guillain-Barré & $\begin{array}{l}\text { Intracranial } \\
\text { hypertension }\end{array}$ \\
\hline \multicolumn{11}{|c|}{ Included neurologic medicines } \\
\hline Amlodipine & & Biperiden & Carbamazepine & & Aspirin & & Neostigmine & & & Mannitol \\
\hline Aspirin & & $\begin{array}{l}\text { Carbidopa- } \\
\text { levodopa }\end{array}$ & Diazepam & & Ibuprofen & & Pyridostigmine & & & \\
\hline Clopidogrel & & & Ethosuximide & & Paracetamol & & & & & \\
\hline Enalapril & & & Lorazepam & & Propranolol & & & & & \\
\hline Hydralazine $^{a}$ & & & Midazolam & & & & & & & \\
\hline Hydrochlorothiazide & & & Phenobarbital & & & & & & & \\
\hline Simvastatin & & & Phenytoin & & & & & & & \\
\hline \multirow[t]{2}{*}{ Sodium nitroprusside } & & & Valproic acid & & & & & & & \\
\hline & & & $\begin{array}{l}\text { Magnesium } \\
\text { sulfate }\end{array}$ & & & & & & & \\
\hline \multicolumn{11}{|c|}{$\begin{array}{l}\text { Examples of missing neurologic } \\
\text { medicines }\end{array}$} \\
\hline Labetalol $^{\mathrm{b}}$ & Aripiprazole $^{\mathrm{b}}$ & Cabergoline ${ }^{b}$ & Gabapentin & Glatiramer acetate & Amitriptyline ${ }^{a}$ & Amitriptyline $^{a}$ & Azathioprine $^{a}$ & Gabapentin & $\begin{array}{l}\text { Intravenous } \\
\text { immunoglobulin }^{a}\end{array}$ & Hypertonic saline \\
\hline Nicardipine & Donepezil & Entacapone & Lamotrigine $^{b}$ & Interferon beta 1 & Diclofenac & Carbamazepine $\mathrm{a}^{\mathrm{a}}$ & Cyclosporine ${ }^{a}$ & Propranolola & Plasma exchange & \\
\hline \multirow[t]{8}{*}{ rtPA } & Galantamine & Pramipexole ${ }^{b}$ & Levetiracetam & Methylprednisolone $\mathrm{e}^{\mathrm{a}}$ & Ketorolac & Desipramine & $\begin{array}{l}\text { Intravenous } \\
\text { immunoglobulin }\end{array}$ & Primidone & & \\
\hline & Olanzapine $e^{\text {b }}$ & Rasagiline & Oxcarbazepine & & Metoclopramide & Duloxetine & Mycophenolate mofetil & Topiramate & & \\
\hline & Quetiapine $^{\mathrm{b}}$ & Ropinirole $^{b}$ & Topiramate & & Naproxen & Gabapentin & Prednisolone $\mathrm{e}^{\mathrm{a}}$ & & & \\
\hline & Rivastigmine & Selegiline & Zonisamide & & Sumatriptan ${ }^{\mathrm{b}}$ & $\begin{array}{l}\text { Lidocaine } \\
\text { (topical) }\end{array}$ & & & & \\
\hline & & & & & Topiramate & Nortriptyline & & & & \\
\hline & & & & & Valproic acid ${ }^{a}$ & Oxcarbazepine & & & & \\
\hline & & & & & Venlafaxine & Pregabalin & & & & \\
\hline & & & & & & Venlafaxine & & & & \\
\hline
\end{tabular}

a Medication on the Model List approved for a different indication.

${ }^{\mathrm{b}}$ Medication rejected from essential medicines list inclusion. 


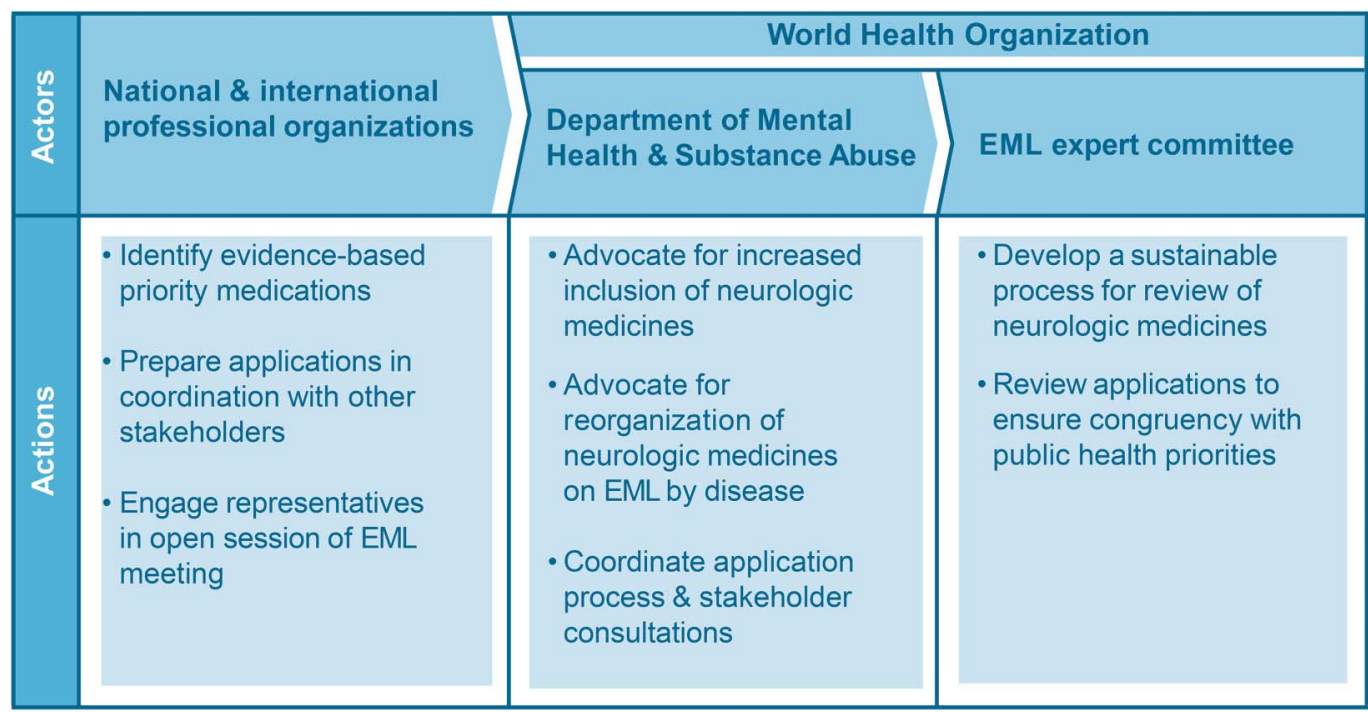

$E M L=$ essential medicines list.

of application submissions and inadequate neurologic or neuropharmacologic expertise on the Expert Committee. The procedure for updating the EML underwent transition in 2002, with increasing emphasis on evidence-based vs experience-based methods. Prior to 2002, when the number of neurologic medications (i.e., antiepileptic and antimigraine) increased the most, the process of approval and rejection was less transparent. Since 2002, there have been approximately 12 applications, with 2 approvals, of neurologic medications, compared to 68 anti-infective and 24 antineoplastic medication approvals.

The Expert Committee has rejected 7 medications that have indications for neurologic disorders. The rejected neurologic medications and their proposed indications include azathioprine for multiple sclerosis, dopamine agonists for Parkinson disease, labetalol for pregnancy-induced hypertension, lamotrigine for new-onset partial epilepsy or new-onset generalized epilepsy in women contemplating pregnancy, midazolam for prolonged convulsive seizures, the fixeddosed combination polypill for cardiovascular risk factors, and sumatriptan for migraine. Of those medicines, a repeat application for midazolam was later approved for status epilepticus management. The Expert Committee's reasons for rejecting these various applications included poor application quality, limited review of evidence, lack of comparative costeffectiveness analysis, and unclear public health need for the proposed medication.

Essential medicine selection and revising the Model List. Every 2 years an Expert Committee appointed by the WHO's Director-General reviews the Model List. Eight to 15 Expert Committee members are selected on the basis of equitable geographic representation by WHO region, sex balance, and professional background. The majority of prior committee members have been clinical pharmacologists. Around 20 clinical physicians served on the Expert Committee over the last 40 years. Though there has been representation from varied specialties, neurologists have been notably absent from membership. It is unknown whether past members had expertise in neuropharmacology.

Any medication change (i.e., addition, dosage change, or deletion) requires an application submitted to the Expert Committee. There are no restrictions on who may submit an application, and the WHO has accepted submissions from individuals, specialist societies, professional groups, NGOs, and pharmaceutical companies. Essential medicine selection is made on the basis of disease prevalence, public health relevance, evidence on efficacy and safety, and comparative costs and cost-effectiveness. WHO endorses regular update of essential medicine selections to reflect new therapeutic options and changing health care needs.

In order to adequately address the global burden of neurologic disorders, an expansion of neurotherapeutics on the WHO Model List is necessary. First, preparation of evidence-based applications is encouraged for (1) neurologic disorders in need of updated medicine options, and (2) neurologic disorders not covered by the Model List, with priority given to those associated with the greatest mortality and morbidity. Second, neurologists have the opportunity to engage in discussions regarding neurotherapeutics by either attending the open 
session of the Expert Committee meeting or posting commentary on pending applications via the WHO essential medicines website (http://who.int/ selection_medicines/committees/en/) in the months leading up to the meeting. Third, a petition to reorganize neurologic medicines by disease-specific categories would advance the WHO's goal to promote rational use of essential medicines while highlighting current deficiencies on the Model List. Through these multiple approaches, the neurology community is capable of enacting policy change to reduce the treatment gap of high-burden neurologic disorders worldwide. We propose a roadmap for these efforts in the figure.

National and international professional societies (e.g., the American Academy of Neurology and the World Federation of Neurology), specialty societies such as the International League Against Epilepsy and International Headache Society, NGOs that help distribute essential medicines, and other stakeholders (patient representative groups and advocacy groups such as Alzheimer's Disease International) all have a stake in ensuring the inclusion of neurotherapeutics on future editions of the WHO EML. It is imperative that these entities work in consultation with the WHO Mental Health and Substance Abuse Department to submit and monitor the processes for EML revision. The next Expert Committee meeting takes place in March 2017. We call for the neurology community to be more active in advocacy efforts to expand neurologic medicines on the WHO EML. Key information regarding the application process is found at who.int/selection_medicines/committees/ expert/21/en/.

\section{AUTHOR CONTRIBUTIONS}

Kathryn Rimmer: acquisition of data, analysis and interpretation of data, drafting of manuscript. Hiral Shah: critical revision of manuscript for intellectual content. Kiran Thakur: study concept and design, analysis and interpretation of data, critical revision of manuscript for intellectual content.

\section{ACKNOWLEDGMENT}

Tarun Dua, MD, Department of Mental Health and Substance Abuse at the World Health Organization, Program for Neurological Diseases and Neuroscience, Lead Medical Officer, reviewed the manuscript. Jessica
Magrid-Bernstein, MD, Columbia University Medical Center, Department of Neurology, edited the manuscript for non-intellectual content. Mary H. Stratton, BA, Starbucks Global Creative Studio, provided technical assistance with the graphic design of the figure.

\section{STUDY FUNDING}

No targeted funding reported.

\section{DISCLOSURE}

K. Rimmer reports no disclosures relevant to the manuscript. H. Shah is a consultant to the World Health Organization. K. Thakur is a consultant to the World Health Organization and receives NIH funding (1R01HD074944-01A1). Go to Neurology.org for full disclosures.

\section{REFERENCES}

1. GBD 2015 DALYs and HALE Collaborators. Global, regional, and national disability-adjusted life-years (DALYs) for 315 diseases and injuries and healthy life expectancy (HALE), 1990-2015: a systematic analysis for the Global Burden of Disease Study 2015. Lancet 2016;388:1603-1658.

2. GBD 2015 Mortality and Causes of Death Collaborators. Global, regional, and national life expectancy, all-cause mortality, and cause-specific mortality for 249 causes of death, 1980-2015: a systematic analysis for the Global Burden of Disease Study 2015. Lancet 2016;388:14691544.

3. World Health Organization. Atlas: Country Resources for Neurological Disorders. Geneva: World Health Organization; 2004.

4. Laing R, Waning B, Gray A, Ford N, t Hoen E. 25 years of the WHO essential medicines lists: progress and challenges. Lancet 2003;361:1723-1729.

5. Bazargani YT, Ewen M, de Boer A, Leufkens H. Essential medicines are more available than other medicines around the globe. PLoS One 2014;9:e87576.

6. World Health Organization. WHO Model List of Essential Medicines, 19th List (April 2015): amended November 2015 [online]. Available at: who.int/medicines/publications/ essentialmedicines/en/. Accessed November 2, 2016.

7. Robertson J, Magrini N, Barr R, Forte G, Ondari C. Medicines for cancers in children: the WHO model for selection of essential medicines. Pediatr Blood Cancer 2015;62:1689-1693.

8. Shulman LN, Torode J, Wagner C, de Lima Lopes G, Barr R, Margin N. WHO Expands Cancer Essential Medicines List [online]. Available at: am.asco.org/ daily-news/who-expands-cancer-essential-medicines-list. Accessed October 21, 2016. 


\section{Neurology}

\section{Expanding medicines for neurologic disorders on the WHO Model List Kathryn Rimmer, Hiral Shah and Kiran Thakur \\ Neurology 2017;88;e87-e91 \\ DOI 10.1212/WNL.0000000000003691}

This information is current as of March 6, 2017

\section{Updated Information \& Services}

\section{References}

Citations

Subspecialty Collections

Permissions \& Licensing

Reprints including high resolution figures, can be found at: http://n.neurology.org/content/88/10/e87.full

This article cites 5 articles, 0 of which you can access for free at: http://n.neurology.org/content/88/10/e87.full\#ref-list-1

This article has been cited by 2 HighWire-hosted articles: http://n.neurology.org/content/88/10/e87.full\#\#otherarticles

This article, along with others on similar topics, appears in the following collection(s):

\section{Medical care}

http://n.neurology.org/cgi/collection/medical_care

Public health

http://n.neurology.org/cgi/collection/public_health

Information about reproducing this article in parts (figures,tables) or in its entirety can be found online at:

http://www.neurology.org/about/about_the_journal\#permissions

Information about ordering reprints can be found online:

http://n.neurology.org/subscribers/advertise

Neurology ${ }^{\circledR}$ is the official journal of the American Academy of Neurology. Published continuously since 1951, it is now a weekly with 48 issues per year. Copyright @ 2017 American Academy of Neurology. All rights reserved. Print ISSN: 0028-3878. Online ISSN: 1526-632X.

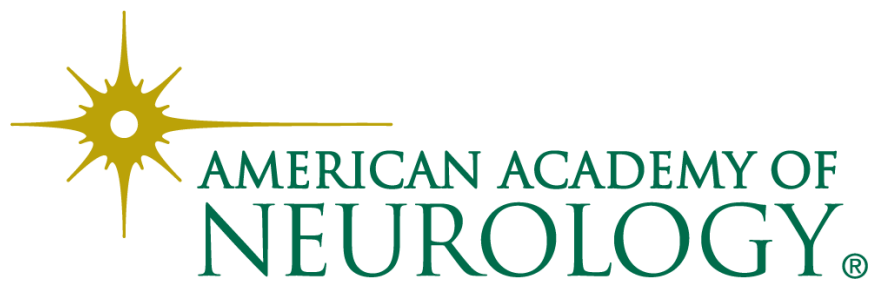

